\title{
REDUCED SWITCH COUNT CONVERTER FOR SWITCHED RELUCTANCE GENERATORS
}

\author{
A. V. S. Fleury \\ Laboratório de Física da Universidade Estadual de Goiás \\ Br 153, Anápolis - GO, Brasil \\ afleury@ueg.br \\ F. S. e Silva; W. R. H. de Araújo \\ Laboratório de Máquinas e Acionamentos Elétricos da Universidade Católica de Goiás \\ Praça Universitária, 1440, Goiânia - GO, Brasil \\ felippe@ucg.br; wanderson.senai@sistemafieg.org.br \\ D. A. de Andrade; A. W. F. V da Silveira \\ Laboratório de Acionamentos Elétricos da Universidade Federal de Uberlândia \\ Campus Santa Mônica, Uberlândia - MG, Brasil \\ darizon@ufu.br,gutofleury@gmail.com
}

\begin{abstract}
This paper deals with electronic converters to drive the switched reluctance generator - SRG. An alternative reduced switch count converter is compared with the conventional asymmetric half bridge converter. The SRG is driven with constant speed and excited with DC power from a three-phase rectifier bridge and supplies pulsed DC power to the load at the output. Mathematical and computing models for the SRG are presented, as well as simulation and experimental results. The aim is to show that the alternative converter, which is cheaper, works better than the half bridge converter commonly used to drive these machines.
\end{abstract}

Keywords - Reduced switch count converter, switched reluctance generator.

\section{INTRODUCTION}

The switched reluctance machine is an old idea with an important history [1] and represents one of the simplest types among all the known electrical machines [2]. Modern power electronic converters associated with microprocessing control hardware have brought competitiveness to the switched reluctance machine driven systems, allowing their efficient and reliable use. Constructively the switched reluctance machines present doubly salient poles structure [3], with the phase coils wound in the stator poles making concentrated windings electrically independent per phase. There are no conductors in the rotor and as a consequence, it presents minimal thermal loss [4]. These machines are easy to construct and to maintain. Their most commonly quoted advantages are: absence of permanent magnets [2], low manufacturing costs, reliability, robustness, efficiency [5], high power density, wide operational speed range, fault tolerance and ability to work in harsh environment. Fig. 1 shows parts of a prototype assembled to do the tests whose results are presented in this work.

An inherent characteristic of these machines is a strong magnetic discontinuity that results in current, voltage and torque ripples [6]. Besides, the power electronics

Artigo submetido em 20/06/2007. Revisões em 16/08/2007 e 16/04/2008. Aceito por recomendação do editor F. L. M. Antunes. requirements for its driving are occasionally quoted as a disadvantage, as controversial as it can be, particularly in the context of variable speed applications. There is some operational noise and the machine control is somewhat complex. Common applications are: those related to the More Electric Aircrafts - MEA projects [7]; as startergenerators for cars; wind energy converter systems[5] and hybrid vehicles applications.

Switched reluctance machines can work as motors or as generators just by changing their switching angles [8,9]. Albeit the device is the same, the Switched Reluctance Generator (SRG) is different from the Switched Reluctance Motor (SRM) in some specific and essential aspects: the SRG has a mechanical input for power and an electrical input for excitation. Its output is the electrical power supplied to the load. The SRG presents two different electric circuit configurations per phase: one for the excitation period and another for the generation period. The SRM has an electrical input, a mechanical output and just one electric circuit per phase. As can be expected, there are converter topologies that work well with SRG but are not adequate for SRM. Despite this, due to a heritage from the SRM, the SRG driving commonly uses a half-bridge converter topology.

This paper shows that for the SRG there is at least an alternative converter that is more advantageous. This converter is compared with the traditional half-bridge and its advantages are emphasized.

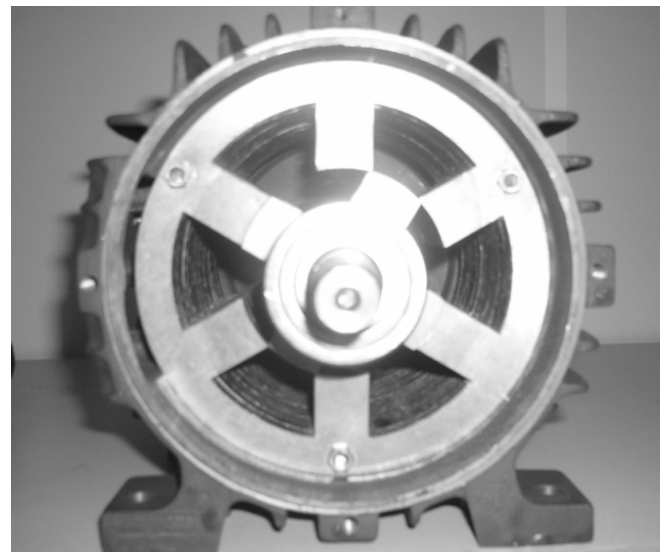

Fig. 1. Parts of a Switched Reluctance Generator - SRG Prototype. 


\section{ENERGY CONVERSION}

The following nomenclature is used in the text:

$\begin{array}{ll}v & \text { Applied voltage. } \\ i & \text { Phase current. } \\ R & \text { Phase resistance. } \\ L & \text { Phase inductance. } \\ e & \text { Back electromotive force. } \\ \omega & \text { Rotor angular speed. } \\ C_{m} & \text { Applied mechanical torque. } \\ C_{e m a g} & \text { Electromagnetic torque. } \\ J & \text { Moment of inertia. } \\ D & \text { Coefficient of friction. } \\ \lambda & \text { Flux linkage. } \\ \theta & \text { Rotor angular position. } \\ W_{x}^{c o} & \text { Co-energy of the phase } x . \\ t & \text { Time } \\ n & \text { Number of phases }\end{array}$

In a SRG mechanical power achieved from a prime mover through a shaft is converted into electrical power. When a pole of the rotor is aligned with the excited pole of the stator, there is a state of stable equilibrium. Thus, in the SRG there is a natural tendency to align the rotor and the stator active poles, in order to maximize the inductance of that phase and to establish a minimal reluctance. When an external mechanical agent forces the rotor to leave the stable equilibrium position, the electromagnetic torque produced results in a back electromotive force that increases the applied voltage. In this way the machine generates electrical power.

The electrical equation for a phase of the SRG is:

$$
v=R i+L \frac{d i}{d t}+e
$$

The back electromotive force is given by:

$$
e=i \cdot \omega \cdot \frac{\partial L}{\partial \theta}
$$

where:

$$
\omega=\frac{d \theta}{d t}
$$

The stator winding is fed in DC. As $\omega$ and $i$ are both positive, the sign of $e$ is the same as that of $\frac{\partial L}{\partial \theta}$. From (2) it can be seen that when $\frac{\partial L}{\partial \theta}>0$ the back electromotive force is positive. In this case, electric power is converted to mechanical power and the machine works as a motor. But when $\frac{\partial L}{\partial \theta}<0$ the back electromotive force is negative and it increases the current converting mechanical power into electrical power [8].

The dynamic mechanical equation for the SRG is given by (3). It is to be noted that the electromagnetic torque $C_{\text {emag }}$ comes as a negative quantity, i. e., acting against the rotor mechanical speed.

$$
C_{m}+C_{\text {emag }}-J \frac{d \omega}{d t}-D . \omega=0
$$

The co-energy of a phase of this machine is given by:

$$
W^{c o}=\int_{0}^{i} \lambda d i
$$

And the corresponding electromagnetic torque for an $n$ phase SRG is given by:

$$
C_{\text {emag }}=\sum_{x=1}^{n} \frac{\partial W_{x}^{c o}}{\partial \theta}
$$

The mathematical model regarding a three phase SRG prototype is shown below:

$$
\begin{aligned}
{\left[\begin{array}{c}
v_{a} \\
v_{b} \\
v_{c} \\
C_{m} \\
0
\end{array}\right]=\left[\begin{array}{ccccc}
R_{a} & 0 & 0 & 0 & 0 \\
0 & R_{b} & 0 & 0 & 0 \\
0 & 0 & R_{c} & 0 & 0 \\
-r_{a} / i_{a} & -r_{b} / i_{b} & -r_{c} / i_{c} & D & 0 \\
0 & 0 & 0 & -1 & 0
\end{array}\right] \cdot\left[\begin{array}{c}
i_{a} \\
i_{b} \\
i_{c} \\
\omega \\
\theta
\end{array}\right]+} \\
+\left[\begin{array}{ccccc}
L_{a} & 0 & 0 & 0 & i_{a} \frac{\partial L_{a}}{\partial \theta} \\
0 & L_{b} & 0 & 0 & i_{b} \frac{\partial L_{b}}{\partial \theta} \\
0 & 0 & L_{c} & 0 & i_{c} \frac{\partial L_{c}}{\partial \theta} \\
0 & 0 & 0 & J & 0 \\
0 & 0 & 0 & 0 & 1
\end{array}\right] \cdot\left[\begin{array}{c}
0 \\
i_{a} \\
\dot{i}_{b} \\
\dot{i_{c}} \\
\dot{\omega} \\
\dot{\theta}
\end{array}\right]
\end{aligned}
$$

where:

$$
r_{a}=\frac{\partial W_{a}^{c o}}{\partial \theta} ; r_{b}=\frac{\partial W_{b}^{c o}}{\partial \theta} \text { and } r_{c}=\frac{\partial W_{c}^{c o}}{\partial \theta}
$$

If the matrices above are designated $[V],[R],[I],[L]$ and $[I]$ exactly in the order they appear in (6), the matrix of states for the SRG has the form:

$$
\dot{[I}]=[L]^{-1}[V]-[L]^{-1}[R][I]
$$

Those non-linear differential equations are solved with numerical methods.

\section{COMPUTING MODEL}

To construct the mathematical model, a three phase 6/4 prototype was considered. Measurements of the flux linkage $(\lambda)$ were done for many rotor positions $(\theta)$, also considering different current values for each one of them. These measurements resulted in a large data bank of the function $\lambda(\theta, i)$. Using this data bank, a program for polynomial interpolation was developed to represent the inductance of a phase as a function of its current and the instantaneous rotor position. Figure 2 shows the inductance of a phase obtained from the polynomial equation for $L(\theta, i)$. 


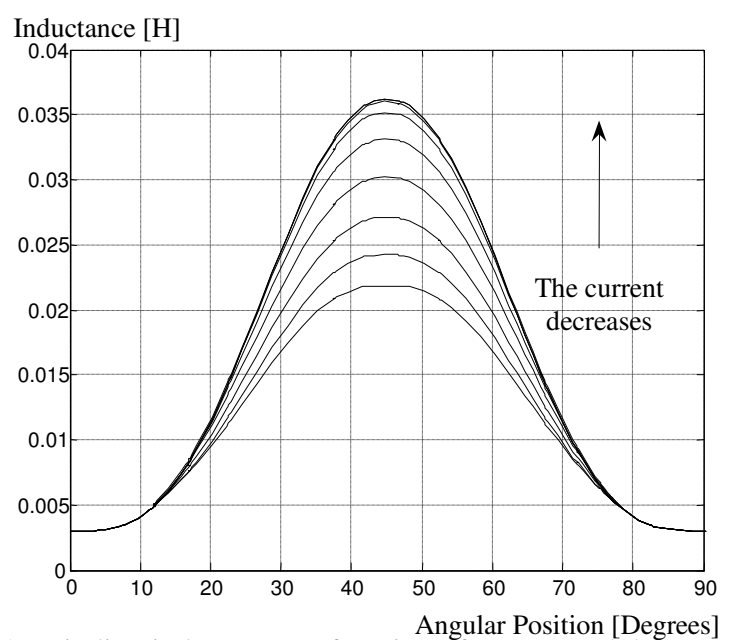

Fig. 2. Winding inductance as function of current and the angula position [10].

Two different converter topologies were used to drive the machine. The first one was the conventional half-bridge (HB) converter shown in Figure 3. This converter uses two diodes and two switches per phase. The second one, shown in Figure 4 is the alternative reduced switch count (RC) topology and uses only one switch and diode per phase. This cheaper topology is devoted to the SRG and does not work with a SRM. In Figure 3 and Figure 4, Q1...Qn, are semiconductors switches like MOSFET's, while D1...Dn, are diodes.

In both topologies, the excitation power comes from a rectified AC source. The excitation period of each phase begins when its switches are turned on and start conducting. At this moment the inductance is still increasing and an electromotive force acting against the current flow is induced in the winding. There is no current to the load as the diodes are inverse biased. The generating period starts when the controlled switches in the HB topology or the only controlled switch in the RC topology are turned off. The phase current path is deviated to the load through the diodes, which are now directly biased due to the inversion of the motion voltage induced in the winding. Note that during this time the sign of $\frac{\partial L}{\partial \theta}$ has changed. Figure 5 shows the active equivalent circuits during the excitation and generation periods. The equivalent circuits for both converters differ only in the voltage drops caused by the semiconductors resistances that are twice as much in the HB configuration. Figure 6 shows the process described above.

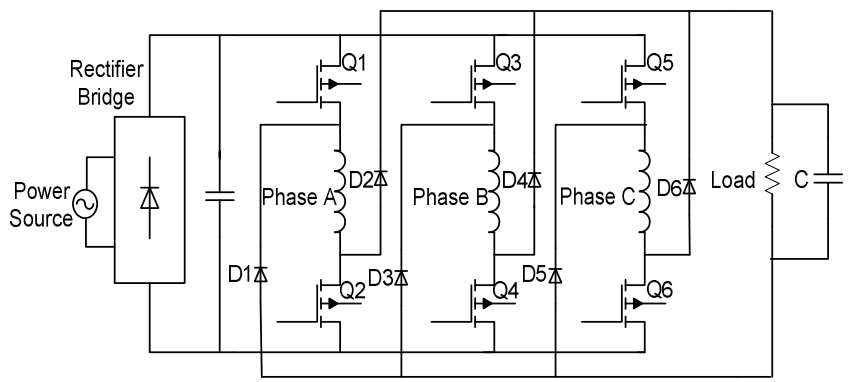

Fig. 3. Electrical scheme of the half-bridge converter.

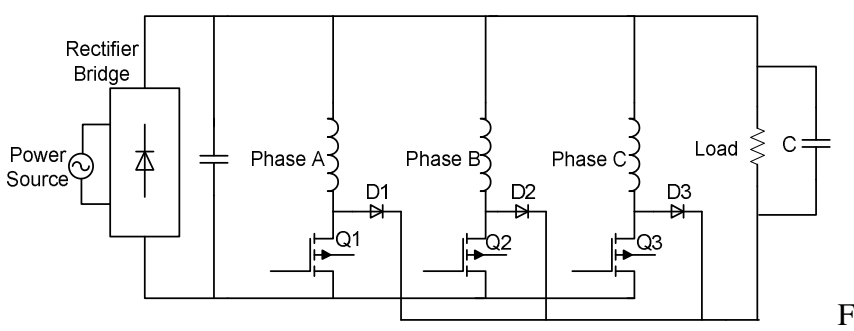

ig. 4. Electrical scheme of the alternative converter.

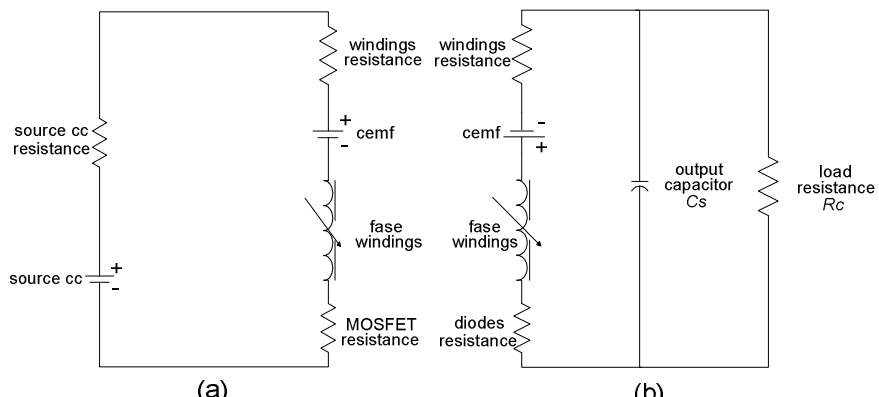

Fig. 5.Electrical scheme of the excitation (a) and generation (b) for both $\mathrm{HB}$ and $\mathrm{RC}$ converters.

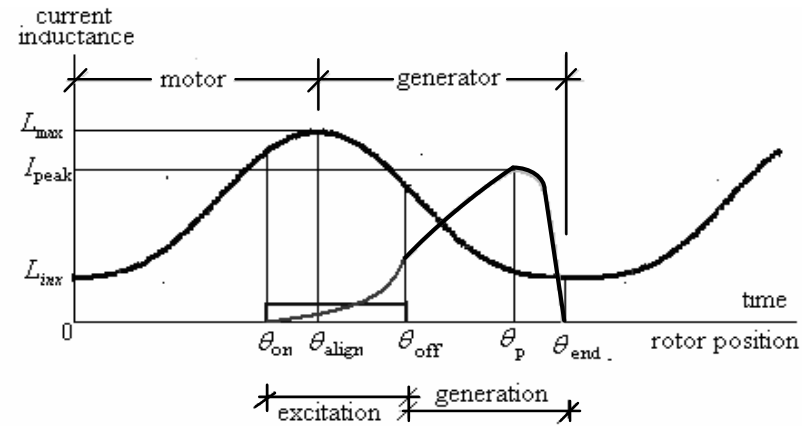

Fig. 6. Excitation and generation periods.

In Figure 6, the parameters $\theta_{\text {on }}, \theta_{\text {align }}, \theta_{\text {off }}, \theta_{P}$ and $\theta_{\text {end }}$ means, respectively, the angular position when the phase is fired, the angular position when the stator and rotor are aligned, the angular position when the phase is turned off, the angular position when the phase current is maximized and the angular position when the generation period is over. $L_{\text {min }}$, $I_{\text {peak }}$ and $L_{\max }$ represent the minimum phase inductance, the peak current and the maximum phase inductance.

For these two converter topologies the mathematical model was checked using a computing program. The inputs were the phase voltages and the mechanical torque.

The outputs are the phase currents, the angular speed and the rotor position. Each new set of values for the phase voltages and the torque is used as a new input in the program to evaluate the next state. The equation system is evaluated considering the saturation effects. The program uses dynamic values that result from the relationship among the components of the converter circuit and from the relations among them and the CA source, the rectifier bridge, the machine and the load. Only the information of the rotor position is necessary to control the gate signals. This simulation strategy allows checking the converter behavior under different circumstances like torque, speed or load changes. 


\section{SIMULATIONS RESULTS}

The simulations were done using data from a prototype of SRG. Its parameters and dimensions are given in Table I. Each phase winding has 50 turns of copper wire AWG 15. The driving strategy states that each phase is fired during 30 degrees and just one phase is fired at time. The SRG was simulated under different conditions. Simulation results at a typical speed of $900 \mathrm{rpm}$, using the alternative converter topology, are presented. Figure 6 shows the DC voltages and currents at the input (VE, IE) and at the output (VS, IS) of the converter, and the phase current.

TABLE I

Characteristics of SRG used

\begin{tabular}{|c|c|c|}
\hline Parameter & Value & Units \\
\hline Stator Diameter & 140 & $\mathrm{~mm}$ \\
\hline Rotor Diameter & 70 & $\mathrm{~mm}$ \\
\hline Stack Length & 107 & $\mathrm{~mm}$ \\
\hline Air Gap Length & 0.4 & $\mathrm{~mm}$ \\
\hline Stator Teeth Width & 19 & $\mathrm{~mm}$ \\
\hline Rotor Teeth Width & 20 & $\mathrm{~mm}$ \\
\hline Stator Slot & 22.5 & $\mathrm{~mm}$ \\
\hline Rotor Slot & 11.7 & $\mathrm{~mm}$ \\
\hline Stator Yoke & 12 & $\mathrm{~mm}$ \\
\hline Rotor Yoke & 12.4 & $\mathrm{~mm}$ \\
\hline Shaft Diameter & 22 & $\mathrm{~mm}$ \\
\hline Number of turns per phase & 50 & turns/phase \\
\hline Inertia & 0.0028 & kg.m ${ }^{2}$ \\
\hline Coefficient of Friction & 0.026 & N.m.s \\
\hline Inductance (Aligned Position) & 36 & $\mathrm{mH}$ \\
\hline Inductance (Unaligned Position) & 3 & $\mathrm{mH}$ \\
\hline Conducting Angle & 30 & degrees \\
\hline
\end{tabular}

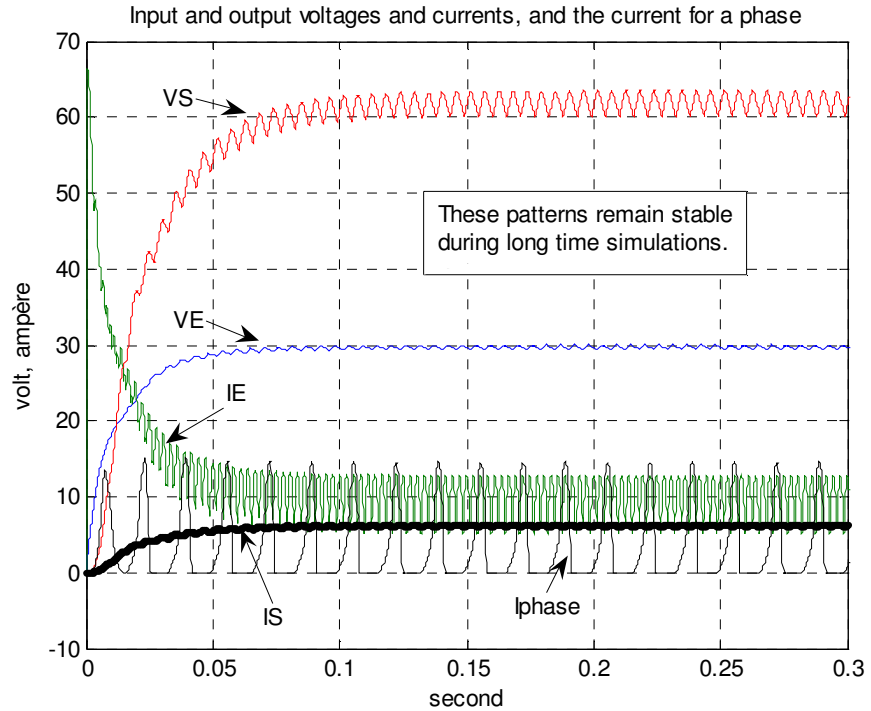

Fig. 7. Input and Output voltages and currents and a phase current.

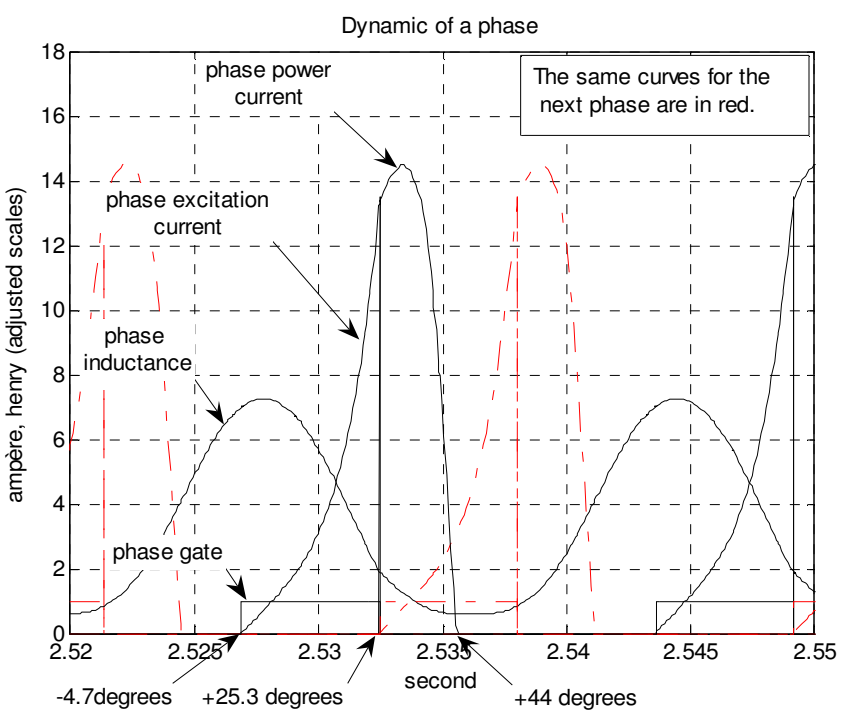

Fig. 8. Dynamics of power generation.

The simulation results for the gate signals, the excitation currents, and the current of power transfer to the load are shown in Figure 8. It can be seen that the conduction angle of the phase switch begins at 4.7 degrees before the peak of the inductance of this phase. The excitation period of this phase ends at 25.3 degrees. From this point on, the phase transfers power to the capacitor and to the load until the rotor reaches the minimum inductance position at around 44 degrees. The dynamic for the next phase is also shown.

It can also be seen in Figure 8 that there is no generating voltage from the end of a phase power transfer to the beginning of the next phase power transfer. Therefore, the SRG transfers power in pulses, and so pointing to the need of an end capacitor to control the load voltage. Therefore, a capacitor is used to smooth the load voltage (VS in Figure 7) and continuously supply the load. It is to be noted that the power used to magnetize the winding during the excitation period, together with the converted power from mechanical supply is completely transferred to the load during generation. It is a particular characteristic of the SRG which reflects positively in its energy conversion efficiency as compared to the traditional generators that do not take advantage of the excitation power being delivered to the load.

The voltage that excites a phase winding is the rectified voltage (VE), as shown in Figure 4. During the excitation process the phase switch is conducting and its diode is not conducting as it is inversely biased. When the power switch is turned off, the diode becomes directly biased and starts conducting. As a result, current flows to the load, driven by the motion voltage induced in the winding.

With the alternative converter topology, running at 900 rpm under stable conditions, the system absorbs $81.6 \mathrm{~W}$ from the AC source and $87 \mathrm{~W}$ from the mechanical source. The converter supplies $165 \mathrm{~W}$ to the load with these two inputs. The electric resistances of the windings, the switches, and the diodes were considered. There are losses around $3.6 \mathrm{~W}$, located in the windings, and because of it, the net electric power supplied to the load by the SRG is $83.4 \mathrm{~W}$. 
According to the results, in this simulation the SRG presents good efficiency under regular operation.

When a half-bridge converter is used in simulations, the losses increase and, consequently, less power is supplied to the load. To illustrate this, Figure 9 shows a sample of generation loops obtained from simulations under the same conditions using the half-bridge converter and the reduced count switch converter. One can see that the area of the reduced count converter is greater than the other. These areas are proportional to the generated energy and so the SRG generates more energy when driven by the reduced count switched converter.

Operations for long periods of time were simulated. With both converter topologies the model of the machine shows stable behavior running with fixed load and constant speeds.

\section{EXPERIMENTAL RESULTS}

Results of two tests carried out with a SRG prototype, using the half bridge converter and the reduced count switch converter are presented. An uncontrolled rectifier bridge with a capacitor of $20 \mathrm{mF}$ was used to provide the power input from the AC grid. A variable voltage source was used to control the excitation voltage. The converter was assembled with Power MOSFET and diodes. The resistive load was $10.8 \Omega$ and a $5 \mathrm{mF}$ capacitor was used at the output to stabilize the load voltage. Figure 10 shows a picture of the arrangement used for the tests.

During the first test the SRG was driven at $900 \mathrm{rpm}$. The reduced switch count converter was used. The AC side waveforms for the voltage and of the current are shown in Figure 11. As can be observed, voltage and current remain in phase all the time, and so the instantaneous power is always positive indicating the inexistence of reactive power and a unidirectional flow of power from the AC line to the system.

Figure 12 shows the waveforms after the rectifier, which supplied DC voltage to the converter. The measurements were $24.3 \mathrm{~V}$ and $2.5 \mathrm{~A}$ respectively. As result, the DC input power was $60.75 \mathrm{~W}$.

The phase voltage and current during the excitation period are shown in Figure 13. This experimental result is like the one shown in Figure 8, which was obtained with the simulation program. It can be noticed that the back electromotive force became negative when the controlled switch was turned off. This event polarizes the diodes and they start to conduct, supplying power to the end capacitor and the load.

At the load, the voltage and current measured values were $38.1 \mathrm{~V}$ and $3.98 \mathrm{~A}$, resulting $151.6 \mathrm{~W}$. And so the SRG supplied $81.5 \mathrm{~W}$ to the load and all the losses involved in the generation process. This result at the output is shown in Figure 14.

The test bench was developed so that different electronic converters configurations can be obtained by just altering connections. For the second test a half bridge converter configuration was set up. The curves depicted in the previous figures are very close to those obtained using the conventional half bridge converter, except that the measured values were a little different.

The power supplied to the load was $81.5 \mathrm{~W}-77.4 \mathrm{~W}=4.1$ $\mathrm{W}$ less than when the half bridge converter was used. The difference is about $5 \%$. It means more losses with more Power MOSFET and diodes, as would be expected. With such result the lower power losses using the reduced count switch converter is confirmed.

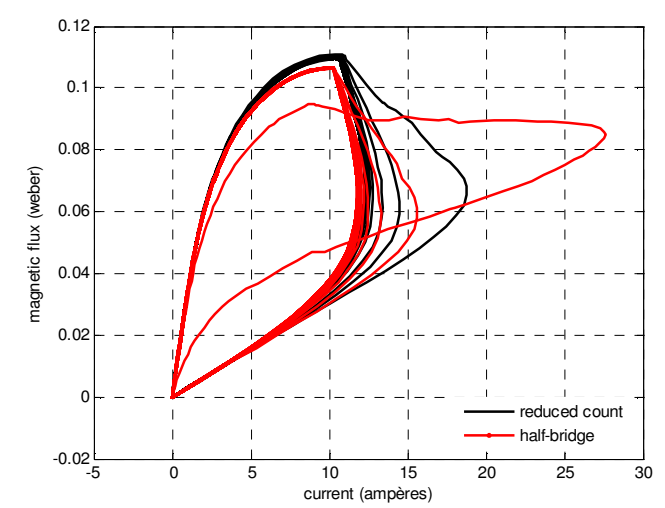

Fig. 9. Generation loops for half-bridge converter and for the reduced switched count converter.

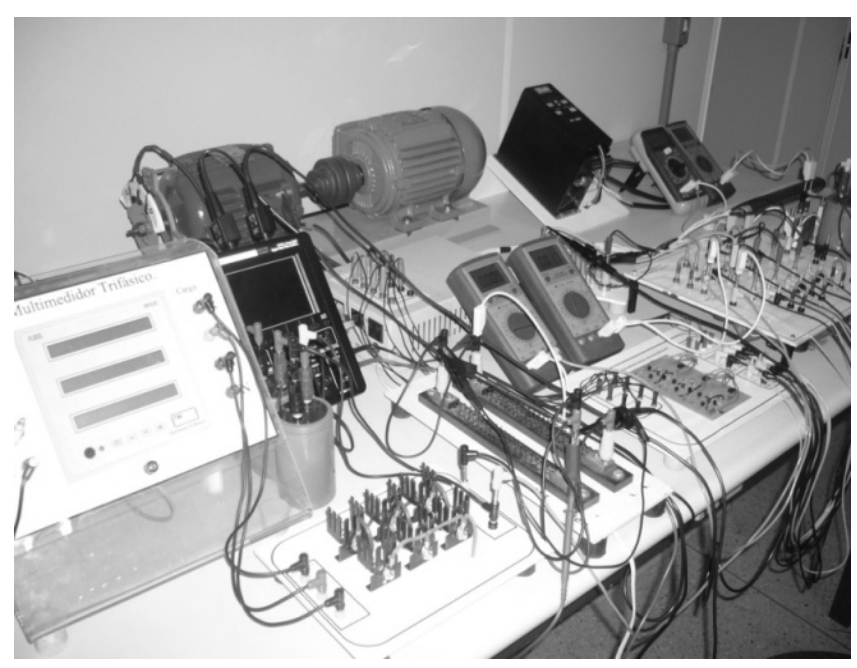

Fig. 10. The arrangement used for experimental tests.

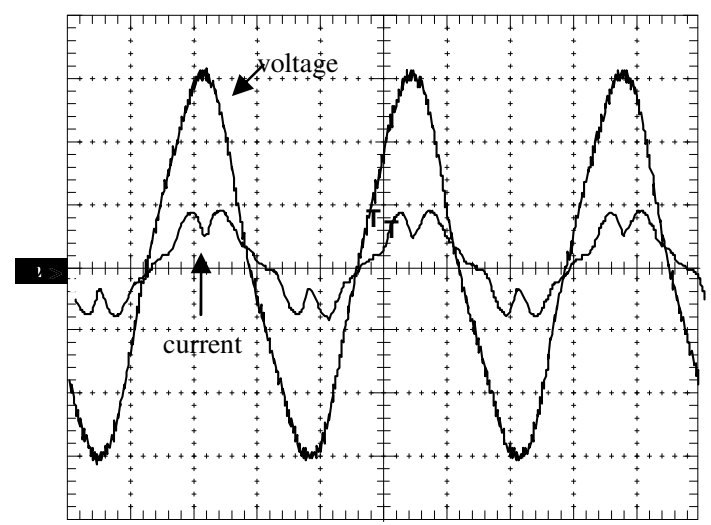

Fig. 11. AC voltage and current waveforms before the rectifier.

At the DC input of the half bridge converter the voltage was $24.4 \mathrm{~V}$ and $2.47 \mathrm{~A}$, resulting in a $60.3 \mathrm{~W}$ power input. The measurements at the output were $37.2 \mathrm{~V}, 3.7 \mathrm{~A}$ and 137.6 W. So, in this case, the SRG generated $77.4 \mathrm{~W}$ and all the losses in the generating process. 


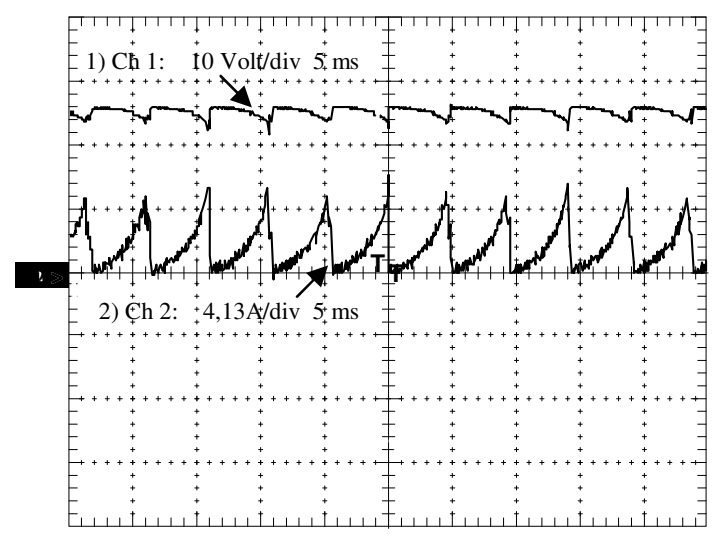

Fig. 12. Voltage and current waveforms after the rectifier.

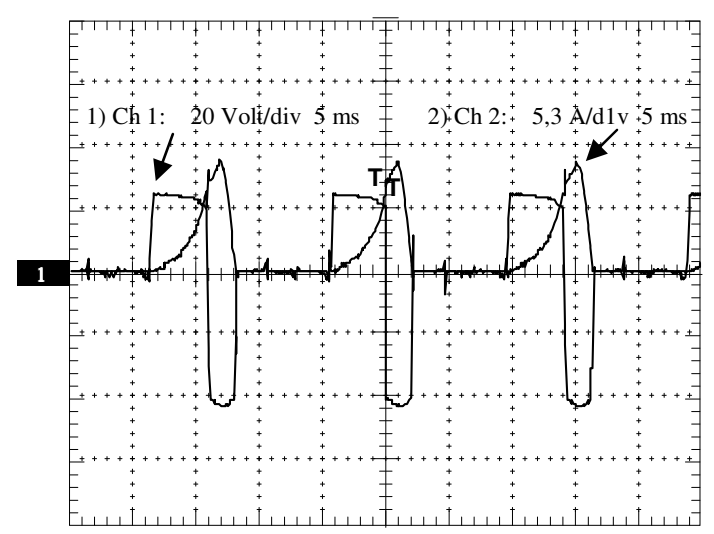

Fig. 13. Phase voltage and current using the alternative converter.

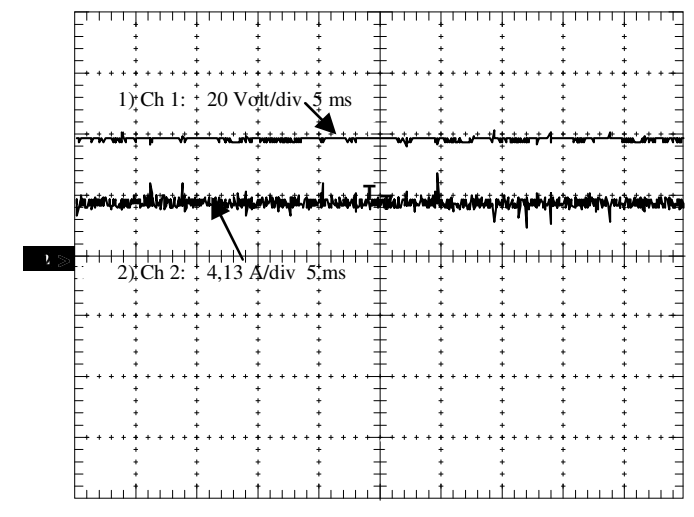

Fig.14. Voltage and current at the output.

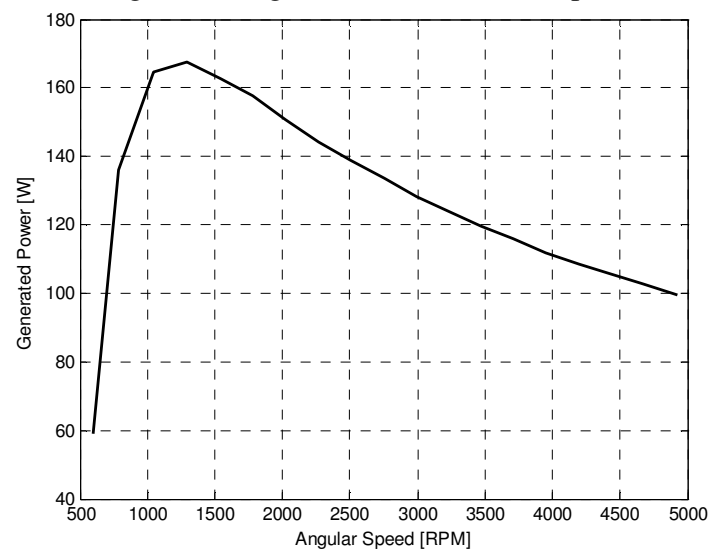

Fig. 15. Generated power as function of angular speed using the half-bridge converter.
The power supplied to the load was $81.5 \mathrm{~W}-77.4 \mathrm{~W}=4.1$ $\mathrm{W}$ less than when the half bridge converter was used. The difference is about $5 \%$. It means more losses with more Power MOSFET and diodes, as would be expected. With such result the lower power losses using the reduced count switch converter is confirmed.

Other experimental results showed that the SRG runs successfully at many other fixed speeds around the typical speed of $900 \mathrm{rpm}$, suggesting that this machine could work well under variable speed. To analyze the behavior of the rated power as a function of the rated speed the machine was run at different speeds, from $600 \mathrm{rpm}$ to $5000 \mathrm{rpm}$. A halfbridge converter was used in this test to insulate the phase winding from the rectifier bridge during a generation pulse. Figure 15 shows the results where the behavior of the generated power from low speed to high speed can be seen. The maximum generated power occurs at around $1300 \mathrm{rpm}$.

\section{CONCLUSIONS}

The SRM operation as a generator was simulated and experimented successfully, using two different converter topologies. Dynamic integrated simulations were performed using a system composed of supply, drives, machine, and load. The system was implemented in laboratory to validate the simulation results. The two converters allowed supplying the load using the power generated by the SRG together with the portion of power coming from the three-phase source through a rectifier bridge. All the power that flowed to the load crossed the converter and the SRG windings. The half bridge converter presented greater global losses than those observed using the reduced switches count alternative converter. This last converter is really cheaper than the conventional half bridge converter. Test results showed that the SRG was stable at constant speed. Other tests showed that the SRG is able to work in a wide speed range. Thus, the SRG emerges as an available alternative for special applications such as grid connected operation using variable speed prime mover.

\section{ACKNOWLEDGEMENTS}

The authors are grateful to the Universidade Estadual de Goiás, to the Universidade Católica de Goiás, to the Universidade Federal de Uberlândia and to the Serviço Nacional de Aprendizagem Industrial for their support to this work.

\section{REFERENCES}

[1] A.F. Anderson; "Development history, Electronic Control of Switched Reluctance Machines", Newness Power Engineering Series, Ed. T. J. E. Miller, Oxford, pp. 6-33.

[2] M.K. El-Nemr, M.A. Al-Khazendar, E.M. Rashad, M.A. Hassanin "Modeling and Steady-State Analysis of a Stand-Alone Switched Reluctance Generators", Power Engineering Society General Meeting, 2003, IEEE, Volume 3, 13-17, pp 1894 - 1899.

[3] R. Cardenas, R. Peña, M. Perez, G. Asher, J. Clare, P. Wheeler "Control system for grid generation of a 
switched reluctance generator driven by a variable speed wind turbine", Industrial Electronic Society, 2004. IECON 2004, 30th Annual Conference of IEEE, Vol. 2, 2-6 November. 2004, pp. 1879-1884.

[4] D.A. Andrade, R.S. Costa, R.S. Teixeira, A. Fleury "Energy Efficiency for Fractional Power Loads, Industry Applications Magazine", Vol. 12, No 6, November December 2006, pp. 12-20.

[5] M.A. Mueller "Design and performance of a $20 \mathrm{~kW}, 100$ $\mathrm{rpm}$, switched reluctance generator for a direct drive wind energy converter", IEEE International Conference on Electric Machines and Drives, May 2005, pp. 56-63.

[6] L.O.A.P. Henriques, L.G.B. Rolim, W.I. Suemitsu, P.J. Branco, "Uma Revisão das Estratégias de Redução de Ondulações de Conjugado no Motor de Relutância Chaveado." Eletrônica de Potência - Vol.8, n 1, Junho de 2003.

[7] C. Cossar, T. Sawata "Microprocessor controlled DC power supply for the generator control unit of a future aircraft generator with a wide operating speed range", PEMD 2004, Vol. 2, 31/03-2/04/2004, pp. 458-463.

[8] T. Sawata "The switched reluctance generator, Electronic Control of Switched Reluctance Machines", Newness Power Engineering Series, Ed. T. J. E. Miller, Oxford, pp. 227-251.

[9] P.P. Paula, W.M. Silva, J.R. Cardoso, S.I. Nabeta, "Simulação do Desempenho de Motores e Geradores de Relutância Chaveados" Eletrônica de Potência - Vol. 8, $\mathrm{n}^{\circ} 2$, Novembro de 2003.

[10] G.R. Hwang "Modelagem da máquina a relutância chaveada incluindo a saturação", Dissertação, Universidade Federal de Uberlândia.

[11]C. Ferreira, E. Richter "Performance evaluation of a 250 kW switched reluctance starter generator", Conference Records of the 1995 IEEE Industry Applications Conference, 1995, Vol. 1, pp. 434-440.

\section{BIOGRAPHIC DATA}

Augusto Fleury Veloso da Silveira was born in Goiânia - Brazil, on August 30, 1953. He received the BSc. degree in physics and in electrical engineering both from the Universidade Federal de Goiás, Goiânia, Brazil, both in 1977. He also received the MSc degree in physics from the Universidade Federal de Goias, in 2001, and the Doctorate degree in electrical engineering from the Universidade Federal de Uberlândia, Brazil, in 2008. Nowadays he is going on ahead with researches on Switched Reluctance Machines. From 1978 to 1985 , he was a Lecturer with the Universidade Católica de Goiás. After this he was a Senior Consultant Engineer with the Engevix Engenharia S/C Ltda and later as a Senior Engineer with the Centrais Elétricas do Norte do Brasil S/A - Eletronorte. Presently he is with the Universidade Estadual de Goiás and again with the Universidade Católica de Goiás, in both as a Senior Lecturer. His teaching, research, and consulting interests and activities are related to design, simulation, and control techniques associated with electrical machines and drives, and with alternative power sources. He has authored and coauthored papers published in these areas. He also deals with Nuclear Magnetic Resonance Imaging.
Felippe dos Santos e Silva was born in Anápolis - Brazil, on July 28, 1979. He received his technologic degree in electrotechnics and in telecommunications both from the Centro Federal de Educação Tecnológica de Goiás, Goiânia, Brazil, both in 2001. He also received the BSc. degree in electrical engineering from the Universidade Católica de Goiás, Brazil, in 2008, where he carried out research on Switched Reluctance Machines. Presently he is with the Laboratório de Engenharia Elétrica da Universidade Católica de Goiás and he is working towards the MSc degree in electrical engineering at the Universidade Federal de Goiás, Brazil.

Wanderson Rainer Hilário de Araújo was born in Goiânia - Brazil, on January 15, 1981. He received the technological degree in Communication Networks from the Centro Federal de Educação Tecnológica de Goiás, Goiânia, Brazil, in 2002. He also received the BSc. degree in electrical engineering from the Universidade Católica de Goiás, Goiânia, Brazil, and the MSc. degree in electrical engineering from the Universidade Federal de Goiás, Goiânia, Brazil, in 2003 and in 2006, respectively. He is now working towards the Doctorate degree in electrical engineering at the Universidade Federal de Uberlândia, Brazil. Since 2006 he is with Serviço Nacional de Aprendizagem Industrial and with the Universidade Católica de Goiás as lecturer and researcher. His teaching and research interests and activities are related to power electronics applied to machines driving and control.

Darizon Alves de Andrade (M'87) was born in Monte Alegre de Minas - Brazil, on June 23, 1956. He received the BSc. and MSc. degrees from the Universidade Federal de Uberlândia (UFU), Uberlândia, Brazil, and the $\mathrm{PhD}$. degree from the University of Leeds, Leeds, U.K., in 1980, 1987, and 1994, respectively, all in electrical engineering. During the year 2000, he was a Visiting Scholar with the Motion Control Group, Bradley Department of Electrical Engineering, Virginia Polytechnic Institute and State University, Blacksburg, VA, USA where he carried out research on new strategies for modeling SRMs. From 1980 to 1985, he was a Lecturer with the Faculdade de Engenharia de Ituiutaba, Ituiutaba, Brazil. In 1985, he joined the Faculdade de Engenharia Elétrica, UFU, where he is currently a Senior Lecturer. His teaching, research, and consulting interests and activities are related to design, simulation, and control techniques associated with motion control of electromechanical energy converter devices and new developments in quality of power. He has authored and coauthored several papers in these areas.

Augusto Wohlgemuth Fleury Veloso da Silveira was born in Goiânia - Brazil, on August 27, 1981. He received the BSc. degree in computer engineering from Universidade Católica de Goiás and received his MSc. degree in electrical engineering from Universidade Federal de Uberlândia (UFU). He is currently working toward the Doctorate degree in electrical engineering at Universidade Federal de Uberlândia. His main areas of interest are electrical machines and drives. 